\title{
Evaluating alternative management strategies for bigeye tuna, Thunnus obesus, in the Indian Ocean
}

\author{
YUHE TONG ${ }^{1,4}$, XINJUN CHEN $^{1,2,5}$ and YONG CHEN ${ }^{3,5}$ \\ ${ }^{1}$ College of Marine Sciences, Shanghai Ocean University, Hucheng Ring Road 999, Lingang New City, Shanghai 201306, \\ China. \\ ${ }^{2}$ The Key Laboratory of Sustainable Exploitation of Oceanic Fisheries Resources, Ministry of Education, \\ 999 Hucheng Ring Road, Shanghai 201306, China. \\ ${ }^{3}$ School of Marine Sciences, University of Maine, Orono, Maine 04469, USA. \\ ${ }^{4}$ Current address: Hainan Provincial Fisheries Research Institute, 2 Haixiu Road, Haikou 570206, China. \\ ${ }^{5}$ International Center for Marine Studies, Shanghai Ocean University, China. E-mail: xjchen@ shou.edu.cn
}

SUMMARY: Bigeye tuna (Thunnus obesus) support a large commercial fishery in the Indian Ocean. However, explicit management strategies and harvest control rules are yet to be developed for the management of this fishery. We used a stochastic age-structured production model as an operating model to evaluate several potential management strategies under different assumptions of stock productivity. Five management strategies - constant fishing mortality, constant catch, quasi-constant catch, constant escapement, and status-dependent strategies - were evaluated and compared using the performance indicators including average catch, average spawning stock biomass, variation in catch, average fishing mortality and lowest biomass during the time period considered in the simulation. This study shows that (1) for the constant catch strategy, an annual catch of $90000 \mathrm{t}$ would result in a low risk of stock being overfished while obtaining a stable catch; (2) for the constant fishing mortality strategy fishing mortality of 0.3 per year could yield a higher catch, but might have a high probability (64\%) of stock dropping below the spawning stock biomass (SSB) that could achieve maximum sustainable yield $\left(S S B_{m s y}\right)$; and (3) for the quasi-constant catch strategy an annual catch of $110000 \mathrm{t}$ was sustainable if the current SSB was higher than $S S B_{m s y}$ Constant escapement and status-dependent strategies were robust with respect to different levels of virgin recruitment and steepness. This study suggests that it is important to incorporate uncertainties associated with key life history, fisheries and management processes in evaluating management strategies.

Keywords: Thunnus obesus, management strategy, harvest control rule, Monte Carlo simulation, Indian Ocean, age-structured production model.

RESUMEN: EVALUACIÓN DE LAS ESTRATEGIAS DE GESTIÓN ALTERNATIVAS PARA EL ATÚN PATUDO, THUNNUS OBESUS, EN EL OCÉANO ÍNDICO. - El patudo (Thunnus obesus) soporta una pesquería comercial importante en el Océano Índico. Sin embargo, las estrategias de gestión de reglas de control de las capturas / explícitos aún no se han desarrollado para la gestión de esta pesquería. Se utilizó un modelo estocástico de producción estructurado por edad como un modelo operativo para evaluar varias estrategias de gestión de potenciales bajo diferentes supuestos de productividad de las poblaciones. Se evaluaron cinco estrategias de gestión, la mortalidad por pesca de captura constante, constante, captura casi constante, escape constante, y las estrategias de estado-dependientes, y se compararon con los indicadores de desempeño que incluye la captura promedio, promedio de biomasa de la población reproductora, la variación en la captura, la mortalidad por pesca media, y la biomasa más bajo durante el período de tiempo considerado en la simulación. Este estudio muestra que (1) la estrategia de captura constante, una captura anual de 90 mil toneladas daría lugar a un bajo riesgo de sobreexplotación, mientras se obtiene una captura estable, (2) para la constante de la mortalidad por pesca estrategia de la mortalidad por pesca de 0,3 años podría producir una captura superior, sino que tenga una alta probabilidad (64\%) de las acciones caiga por debajo de la biomasa reproductora del stock (SSB), que podría alcanzar el rendimiento máximo sostenible (RMS; $S S B_{R M S}$ ), y (3) para la estrategia de captura casi una constante anual captura de 110.000 toneladas era sostenible si SSB actual fue superior $S S B_{R M S}$. Escape constante y estrategias de estado-dependientes fueron robustos con respecto a los diferentes niveles de reclutamiento virgen y escarpado. Este estudio sugiere que es importante incorporar las incertidumbres asociadas con ciclo de vida, la pesca y los procesos de gestión en la evaluación de las estrategias de gestión.

Palabras clave: Thunnus obesus, estrategia de gestión, RCC, simulación de Monte Carlo, océano Índico, modelo de producción estructurado por edad. 


\section{INTRODUCTION}

A management strategy, also referred to as a "management procedure" (Bentley and Langley 2012), a "harvest control rule" (Kell et al. 1999, Breen 2009), and a "decision rule" (Bentley et al. 2005), is a group of regulations defined with key management parameters to address certain management objectives (Deroba and Bence 2008). Fishing mortality of the next year can be determined directly or indirectly using a defined management strategy based on the status of the stock and/or exploitation determined in a stock assessment.

Two types of management strategy are often considered: constant rules or one-parameter control rules (Thompson 1999); and status-dependent rules or multiparameter control rules (also known as "precautionary control rules"; Restrepo and Powers 1999). Constant rules keep a single management parameter constant, often including constant fishing mortality rate (CF) and constant catch (CC). They are easy to use, but $\mathrm{CF}$ and $\mathrm{CC}$ rules may have a high risk of resulting in overfishing or even overfished stocks because management regulations usually do not change with the status of populations. Status-dependent rules, which enable management regulations to be adjusted according to the status of populations, are comparatively precautionary in reducing the likelihood of overfishing while achieving optimum yields (Zhang et al. 2011).

The management strategy is often evaluated for its performance to achieve management objectives using a simulation approach in the face of uncertainties (Butterworth 2007). An operational model is often used to simulate population dynamics for evaluating the probability of achieving pre-specified, usually conflicting, management objectives with respect to stock abundance and fishery catch. This helps identify a sustainable exploitation rate and likelihood of recovery of an overfished stock in a defined time duration (Smith 1994). Uncertainties of different sources (e.g. process error, observation error, model error, estimation error and implementation error) should be incorporated in the evaluation of appropriate management strategies. Such approaches to evaluating management strategy were used in the southern bluefin tuna (Thunnus maccoyii) fishery (Polacheck et al. 1999) and many other fisheries (e.g. Needle 2008, Punt and Hobday 2009).

Bigeye tuna (Thunnus obesus) is ecologically important as a top predator in the Indian Ocean ecosystem. It is also economically important as it supports major longline (LL) and purse seine fisheries in the Indian Ocean and annual catch is high and used as major raw materials for sashimi and sushi, especially in recent years when there is a great decrease in bluefin tuna landing. Managed by the Indian Ocean Tuna Commission (IOTC), its annual catch has varied from nearly 81000 tonnes to 140000 tonnes since 2000 (Herrera and Pierre 2009, IOTC 2012), while the estimates of maximum sustainable yield (MSY) ranged from 89090 to 190561 tonnes based on pre- vious studies (Nishida et al. 2002, Ricard and Basson 2002, Shono et al. 2004, 2006, 2009, IOTC 2008), and currently at 114000 tonnes estimated with the stock synthesis model (Kolody and Herrera 2010) and 102 928 tonnes estimated with the age-structured production model (ASPM, Nishida and Rademeyer 2011). To prevent stock from being overfished, annual catch should not exceed MSY levels, which is the major management target in use by IOTC (IOTC 2010, IOTC 2012). Although recent stock assessment suggests that the stock size is slightly above the $\mathrm{B}_{\text {msy }}$ (the biomass that could achieve MSY), there is still great uncertainty about stock status and the potential risk of overfishing (Shono et al. 2009, Kolody and Herrera 2010). No formal management strategy is evaluated by IOTC, and appropriate management options should be identified based on the Kobe strategy matrix, which illustrates the levels of risk associated with varying catch levels over time based on simulation projections (IOTC 2010, 2012). The status of stock was determined by comparing the stock assessment results with MSY-based biological reference points (IOTC 2008). A previous study conducted in our lab showed that complicated status-dependent harvest strategies could drive the bigeye tuna stocks to the desirable status defined by MSY-based biological reference points efficiently, and recommended a further simulation study to evaluate the performance of more biological reference points (BRPs) and harvest control rules (HCRs) in managing this fishery (Zhang et al. 2013).

The objective of this study was to assess potential feasible management methods and management actions including annual a catch limit for the bigeye fishery in the Indian Ocean. We developed a simulation framework to evaluate alternative management strategies under different levels of uncertainty assumed for recruitment dynamics. Observation errors and implementation errors were considered. The management strategies were evaluated using multiple performance indices including catch and spawning stock biomass. The framework can also be applied to evaluate other potential management strategies in future and to identify impacts of other uncertainties. Although the framework was developed for bigeye tuna in this study, it can also be used for other species. The framework is, however, not a full management strategy evaluation framework because it does not include a stock assessment model. It is more like a projection model in nature. We simulated stock assessment uncertainty by adding observation errors in the projected stock biomass in each year.

\section{MATERIALS AND METHODS}

The framework developed in this study has three components: an operating model simulating population dynamics (Fig. 1), management strategies used to manage the simulated fisheries, and indicators used to measure the performance of a management strategy in achieving management objectives. 


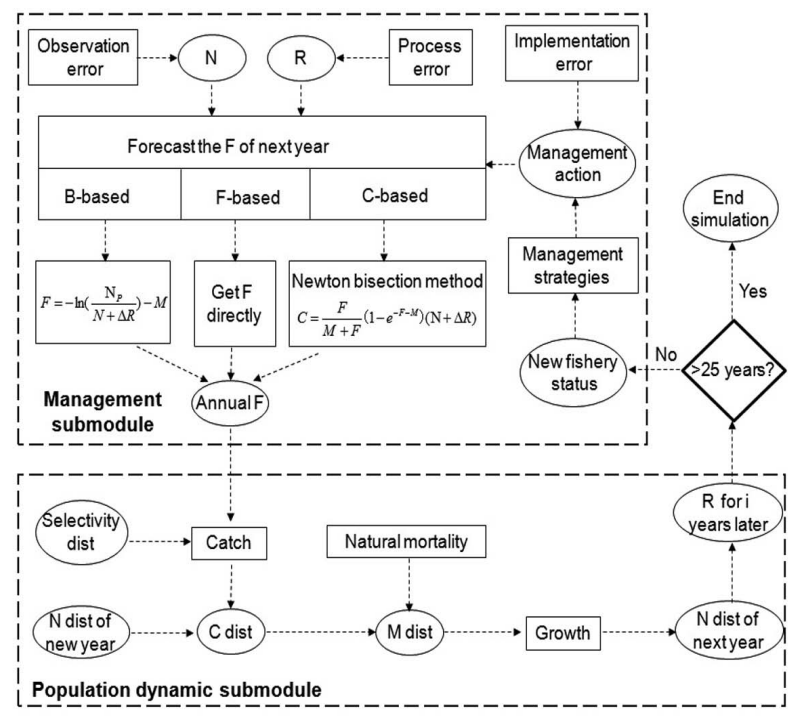

FIG. 1. - Flowchart of the simulation model.

\section{Operating model}

As the operating model to simulate population dynamics, we developed an age-structured production model similar to that developed in Zhang et al. (2013), that used in the bigeye tuna stock assessment in the Indian Ocean (Ricard and Basson 2002, Nishida et al. 2002, Nishida and Shono 2006), and that described in Ricard and Basson (2002). We derived our model from that of Ricard and Basson (2002), but assumed that fishing occurred over the whole year rather than in the middle of a year. To reduce complexity only longline and purse seine fisheries were considered because they covered more than $97 \%$ of total landings in weight before 2005 (IOTC 2012). The stock consisted of nine age groups ranging from age 0 through age 8 "plus" group, which is an aggregated group including fish of age 8 and older. The basic population dynamics are described by the following equation:

$$
C_{y}=C_{y}^{\text {target }} \mathrm{e}^{\eta-\sigma_{C}^{2} / 2} \eta \sim N\left(0, \sigma_{C}^{2}\right)
$$

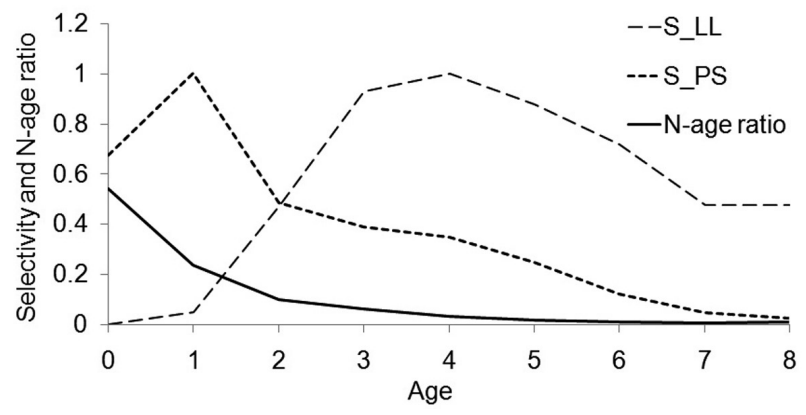

FIG. 2. - Selectivity and N-at-age ratio used to parameterize the operating model in simulating the dynamics of bigeye tuna stock (S_LL, selectivity of longline; S_PS, selectivity of purse seine; Nage, number-at-age). where $N_{y, a}$ is the number of tuna of age $a$ at the beginning of year $y ; m$ is the maximum age (treated as a plus-group set at 8 years in this study); $M_{a}$ is the natural mortality rate of age $a$ (per year, Table 1 ); $R_{y}$ is the recruitment assumed to occur at the start of year $y$; and $F_{y, a}$ is the total fishing mortality rate for age $a$ in year $y$. $F_{y, a}$ can be described as

$$
F_{y, a}=S_{a}^{\mathrm{LL}} r F_{y}+S_{a}^{\mathrm{PS}}(1-\mathrm{r}) F_{y}
$$

where $r$ is the ratio of fishing mortality rate for longline to the total fishing mortality rate, and $S_{a}{ }^{\mathrm{LL}}$ and $S_{a}{ }^{\mathrm{PS}}$ are the selectivities of longline and purse seine fisheries for fish of age $a$, respectively (Fig. 2).

The total "targeted" catch in year $y$ is given by the pre-set management strategies, the "realized" catch is given by Equation (3), and the fully-selected fishing mortality rate in year y can then be solved using Equations (2) and (4), and is used to update the dynamics:

$$
\begin{gathered}
C_{y}=C_{y}^{\mathrm{target}} \mathrm{e}^{\eta-\sigma_{C}^{2} / 2} \eta \sim N\left(0, \sigma_{C}^{2}\right) \\
C_{y}^{\mathrm{targ} e t}=\sum_{a=0}^{m} N_{y, a}\left(1-\mathrm{e}^{-\left(M_{a}+F_{y, a}\right)}\right) W_{a+0.5} F_{y, a} /\left(M_{a}+F_{y, a}\right)
\end{gathered}
$$

where $F_{y}$ is the fully-selected fishing mortality rate in year $\mathrm{y}, W_{a+0.5}$ is the average weight of age $a$ fish in the middle of the year; $C_{y}$ is "actual" catch in year y and the difference between $C_{y}$ and the "targeted" $C_{y}$ target reflects implementation errors assumed to follow lognormal distribution with a standard deviation of $\sigma_{C}$.

Following Ricard and Basson (2002), we took the abundance of 0 -year-old fish as recruitment and assumed that the stock-recruitment relationship follows the Beverton-Holt model:

$$
R_{y}=\frac{4 h R_{0} \mathrm{SSB}_{y}}{\operatorname{SSB}_{0}(1-h)+\mathrm{SSB}_{y}(5 h-1)} \mathrm{e}^{\varepsilon-\sigma_{R}^{2} / 2}, \varepsilon \sim N\left(0, \sigma_{R}^{2}\right)(5)
$$

$R_{y}$ is recruitment in year $y ; h$ is the steepness of the stock-recruitment relationship; $S S B_{0}$ is the average unfished spawning stock biomass; and $R_{0}$ is the virgin recruitment when spawning stock biomass is at $S S B_{0}$. We assumed that the variability in the recruitment followed lognormal distribution with a standard deviation of $\sigma_{R} . S S B_{y}$ is the spawning stock biomass at the beginning of year $y$, which can be written as:

$$
\begin{gathered}
\mathrm{SSB}_{y}=\sum_{a=0}^{8} N_{y, a} \mathrm{Mat}_{a} W_{a} \\
\mathrm{SSB}_{y}^{\mathrm{obs}}=\mathrm{SSB}_{y} \mathrm{e}^{-\sigma_{\mathrm{SSB}}^{2} / 2}, \sim N\left(0, \sigma_{\mathrm{SSB}}^{2}\right),
\end{gathered}
$$

where $\mathrm{Mat}_{a}$ is the proportion of fish mature at age $a ; W_{a}$ is the average weight of fish at age $a$ at the beginning of year; and $S S B_{y}$ obs is the observed spawning stock biomass at the beginning of year $y$ (Ricard and Basson 
TABLE 1. - Values defined for various parameters used in the simulation.

\begin{tabular}{|c|c|c|}
\hline Parameter & Value & Reference \\
\hline $\begin{array}{l}\sigma_{S S B} \\
\sigma_{C} \\
\sigma_{R}\end{array}$ & $\begin{array}{l}0.15 \\
0.20 \\
0.30\end{array}$ & $\begin{array}{l}1 \\
1 \\
1\end{array}$ \\
\hline $\begin{array}{l}F_{0.1} \\
F_{\text {max }} \\
F_{35 \%} \\
F_{20 \%}\end{array}$ & $\begin{array}{l}0.448 \mathrm{yr}^{-1} \\
0.674 \mathrm{yr}^{-1} \\
0.482 \mathrm{yr}^{-1} \\
0.843 \mathrm{yr}^{-1}\end{array}$ & $\begin{array}{l}\text { Calculated by per-recruit model } \\
\text { Calculated by per-recruit model } \\
\text { Calculated by per-recruit model } \\
\text { Calculated by per-recruit model }\end{array}$ \\
\hline $\begin{array}{l}S S B_{2004} \\
B_{2004} \\
F_{2004}\end{array}$ & $\begin{array}{l}430000 \text { tonnes } \\
720000 \text { tonnes } \\
0.29 \mathrm{yr}^{-1}\end{array}$ & $\begin{array}{l}\text { IOTC } 2008 \\
\text { IOTC } 2008 \\
\text { IOTC } 2008\end{array}$ \\
\hline $\begin{array}{l}R_{0} \\
h(\text { steepness }) \\
M \_ \text {mat } \\
L_{50 \_ \text {mat }} \\
M(\text { age }=0,1) \\
M(\text { age } \geq 2) \\
L_{\infty}(\mathrm{cm}) \\
k \\
t_{0} \\
\alpha \_W(L<80 \mathrm{~cm}) \\
\alpha \_W(L<80 \mathrm{~cm}) \\
\alpha \_W(L \geq 80 \mathrm{~cm}) \\
\alpha \_W(L \geq 80 \mathrm{~cm})\end{array}$ & $\begin{array}{l}47946000 \\
0.75 \\
0.25 \mathrm{~cm}^{-1} \\
110.888 \mathrm{~cm} \\
0.80 \mathrm{yr}^{-1} \\
0.40 \mathrm{yr}^{-1} \\
169.06 \mathrm{~cm} \\
0.32 \mathrm{~cm}^{-1} \\
-0.34 \mathrm{yr} \\
0.0000274 \\
2.908 \\
0.00003661 \\
2.90182\end{array}$ & $\begin{array}{l}\text { Shono et al. } 2006 \\
\text { Shono et al. } 2009 \\
\text { Shono et al. } 2009 \\
\text { Shono et al. } 2009 \\
\text { Shono et al. } 2009 \\
\text { Shono et al. } 2009 \\
\text { Stequert and Conand } 2003 \\
\text { Stequert and Conand } 2003 \\
\text { Stequert and Conand } 2003 \\
\text { Poreeyanond } 1994 \\
\text { Poreeyanond } 1994 \\
\text { Nakamura and Uchiyama } 1966 \\
\text { Nakamura and Uchiyama } 1966\end{array}$ \\
\hline
\end{tabular}

Note: M_mat represents instantaneous rate of maturity in the logistic maturity model.

2002). We assumed that the observational errors of SSB followed a lognormal distribution with a standard deviation of $\sigma_{S S B}$. Because we did not have a stock assessment component in the evaluation, the simulation framework developed in this study is not a full management strategy evaluation framework. The observation error was used to reflect estimation errors in SSB in the assessment. However, we did not consider potential auto-correlations in errors associated with stock biomass estimates, which may exist in the estimates derived from stock assessment.
The operating model incorporated uncertainty associated with population and fishery parameters and potential errors for observation and implementation of management strategy (Table 1, Fig. 1). The parameters used in the simulation model were mainly obtained from the IOTC stock assessment reports (Table 1, Fig. 2, Shono et al. 2009). The fishery selectivity parameters were the same as those in Nishida and Shono (2006). The values of standard deviations were determined somewhat arbitrarily, but the levels of standard deviations for different parameters were consistent

TABLE 2. - Parameter values used in each management scenario (HCR, harvest control rule; CF, constant fishing mortality; CC, constant catch; QCC, quasi-constant catch; CE, constant escapement; SD, status-dependent rule).

\begin{tabular}{|c|c|c|c|c|c|}
\hline$\overline{\mathrm{HCR}}$ & Scenario abbreviation & $\begin{array}{l}\text { Specified value } \\
S S B_{T}\end{array}$ & $S S B_{L}$ & Other & \\
\hline $\mathrm{CF}$ & $\begin{array}{l}\text { CF_0.45 } \\
\text { CF_0.3 } \\
\text { CF_0.15 }\end{array}$ & $\begin{array}{l}1 \\
1 \\
1 \\
1\end{array}$ & $\begin{array}{l}\text { / } \\
\text { / } \\
\text { / }\end{array}$ & $\begin{array}{l}F=0.45 \mathrm{yr}^{-1} \\
F=0.3 \mathrm{yr}^{-1} \\
F=0.15 \mathrm{yr}^{-1}\end{array}$ & \\
\hline $\mathrm{CC}$ & $\begin{array}{l}\text { CC_13 } \\
\text { CC_-11 } \\
\text { CC__9 }\end{array}$ & $\begin{array}{l}1 \\
1 \\
1\end{array}$ & $\begin{array}{l}\text { I } \\
\text { 1 } \\
\text { I }\end{array}$ & $\begin{array}{l}C_{T}=130000 \text { tonnes } \\
C_{T}=110000 \text { tonnes } \\
C_{T}=90000 \text { tonnes }\end{array}$ & \\
\hline QCC & $\begin{array}{l}\text { QCC_13 } \\
\text { QCC_11 } \\
\text { QCC_9 }\end{array}$ & $\begin{array}{l}S S B_{m s y} \\
S S B_{m s y} \\
S S B_{m s y}\end{array}$ & $\begin{array}{l}0.5 S S B_{m s y} \\
0.5 S S B_{m s y} \\
0.5 S S B_{m s y}\end{array}$ & $\begin{array}{l}C_{T}=130000 \text { tonnes } \\
C_{T}=110000 \text { tonnes } \\
C_{T}=90000 \text { tonnes }\end{array}$ & \\
\hline \multirow[t]{2}{*}{$\mathrm{CE}$} & $\begin{array}{l}\text { CE_0.6 } \\
\text { CE_0.4 } \\
\text { CE_0.2 }\end{array}$ & $\begin{array}{l}1 \\
1 \\
1\end{array}$ & $\begin{array}{l}0.5 S S B_{m s y} \\
0.5 S S B_{m s y} \\
0.5 S S B_{m s y}\end{array}$ & $\begin{array}{l}\alpha=0.6 \\
\alpha=0.4 \\
\alpha=0.2\end{array}$ & \\
\hline & & & & $F_{T}$ & $F_{L}$ \\
\hline SD & $\begin{array}{l}\text { SD_a } \\
\text { SD_b } \\
\text { SD_c } \\
\text { SD_d } \\
\text { SD_e } \\
\text { SD_f }\end{array}$ & $\begin{array}{l}S S B_{m s y} \\
S S B_{m s y} \\
S S B_{m s y} \\
0.4 S S B_{0} \\
0.4 S S B_{0} \\
0.4 S S B_{0}\end{array}$ & $\begin{array}{l}0.5 S S B_{m s y} \\
0.5 S S B_{m s y} \\
0.5 S S B_{m s y} \\
0.1 S S B_{0} \\
0.1 S S B_{0} \\
0.1 S S B_{0}\end{array}$ & $\begin{array}{l}0.75 F_{m s y} \\
F_{0.1} \\
F_{35 \%} \\
0.75 F_{m s y} \\
F_{0.1} \\
F_{35 \%}\end{array}$ & $\begin{array}{l}F_{\text {msy }} \\
F_{\text {max }} \\
F_{20 \%} \\
F_{\text {msy }} \\
F_{\text {max }} \\
F_{20 \%}\end{array}$ \\
\hline
\end{tabular}

Note: $S S B_{\text {msy }}$ (350000 tonnes), $S S B_{0}\left(1150000\right.$ tonnes) and $F_{m s y}\left(0.300 \mathrm{yr}^{-1}\right)$ are taken from IOTC (2008). 
with those used in other simulation studies (e.g. Chen and Paloheimo 1995, Walters 1998). We assumed that fish growth follows the von Bertalanffy growth function (VBGF), the maturity-length relationship follows logistic function, and the weight-length relationship follows a two-stage allometric model with an inflection point at $80 \mathrm{~cm}$ (Table 1 ). The ratio of $F_{L L}$ vs. $F_{P S}$ was kept constant at the 2002 level $\left(F_{L L} / F_{P S}=3.309\right.$; Shono et al. 2004). For each scenario considered we conducted 250 simulation runs, which yielded stable results. We used the stock status in 2004 as the start point in the simulation (Table 1, IOTC 2008). Because the age composition estimate for the stock abundance in 2004 was not available, we estimated the age composition so that the catch, SSB and stock biomass in 2004 could approximate the reported values in 2004 (Fig. 2, IOTC 2008). The management time period considered was 25 years.

\section{Management strategies}

Eighteen management strategy scenarios were considered, including a constant fishing mortality with three different levels, a strict constant catch rule with three different catch levels, a quasi-constant catch rule with three different catch levels, a constant escapement with three exploitation rates, and a precautionary control rule with six different groups of BRPs (Table 2; Fig. 3).

\section{Constant fishing mortality strategy $(C F)$}

Keeping a stable fishing mortality rate is relatively easy for fishery management and can result in proper stock biomass and long-term yield (Walters and Parma 1996). There are also some conditional constant fishing mortality rules, with a lower fishing mortality or even fishery closure when stock is below a threshold level. In this study, we only considered strict constant

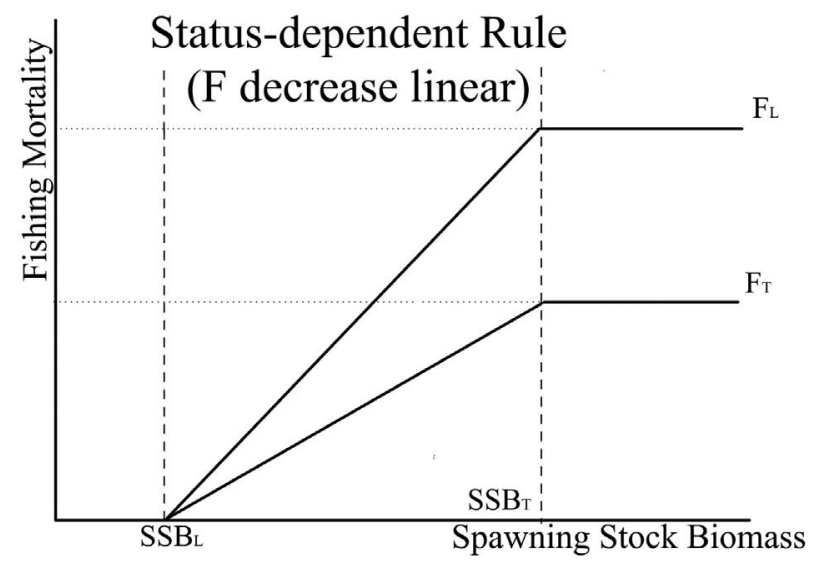

FIG. 3. - Graphic representations of management strategies considered in this study $\left(F_{T}\right.$, target fishing mortality; $F_{L}$, limit fishing mortality; $S S B_{T}$, target spawning stock biomass level, $S S B_{L}$, limit spawning stock biomass level). fishing mortality strategy, and three harvest levels were evaluated.

\section{Constant catch strategy $(C C)$}

The constant catch strategy is also highly operable and widely implemented in many fisheries to set annual quotas for preventing overcapacity and facilitating long-term planning (Hjerne and Hansson 2001). However, the stock may be overfished if stock abundance decline is not detected timely. The annual catch of the three most recent years (from 2006 to 2008) fluctuated around $110000 \mathrm{t}$. We considered catch levels from 90000 to $130000 \mathrm{t}$ with an interval of $20000 \mathrm{t}$. This range covers the current catch level, allowing us to determine whether the current annual catch is sustainable. Catch goals set in the simulation could only be abandoned when stock biomass was too low to support the annual catch. This management strategy can be written as

$$
C_{y}^{\text {target }}=\left\{\begin{array}{lll}
0 & \text { if } & \mathrm{SSB}_{y}^{\prime}>\mathrm{SSB}_{y}^{\mathrm{obs}} \\
C_{T} & \text { if } & \mathrm{SSB}_{y}^{\mathrm{obs}} \geq \mathrm{SSB}_{y}^{\prime}
\end{array}\right.
$$

where $C_{T}$ is the annual catch target set based on a given constant catch rule, $C_{y}^{\text {target }}$ is annual catch to be requested in year $y$, and $S S B_{y}{ }^{\prime}$ is the lowest spawning stock biomass associated with biomass in year $y$ that could sustain $C_{T}$ in year $y$ (calculated by the catch equation with $\mathrm{F}$ at $5 \mathrm{yr}^{-1}$ when $C_{T}$ is achieved).

\section{Quasi-constant catch strategy (QCC)}

A strict constant catch strategy has no feedback to accommodate changes in stock biomass and may lead to stock being overfished. We tested a quasi-constant catch strategy with three scenarios in our study (Hjerne and Hansson 2001). It allows a lower constant catch, usually half of the normal level, when observed spawning stock biomass is lower than the pre-established target spawning stock biomass level $\left(S S B_{T}\right)$, and the fishery is closed if observed spawning stock is lower than the limit spawning stock biomass level $\left(S S B_{L}\right)$. This management strategy can be written as

$$
C_{y}^{\text {target }}= \begin{cases}0 & \text { if } \quad \mathrm{SSB}_{L}>\mathrm{SSB}_{y}^{\text {obs }} \\ C_{T} / 2 & \text { if } \mathrm{SSB}_{T}>\mathrm{SSB}_{y}^{\text {obs }} \geq \mathrm{SSB}_{L} \\ C_{T} & \text { if } \quad \mathrm{SSB}_{y}^{\text {obs }} \geq \mathrm{SSB}_{T}\end{cases}
$$

\section{Constant escapement strategy $(C E)$}

The constant escapement strategy, also referred to as the "fraction/minimum biomass strategy" (Ishimura et al. 2005), is intended to keep stock biomass above its 
minimum level in theory. It can be defined as

$$
C_{y}^{\text {target }}= \begin{cases}0 & \text { if } \mathrm{SSB}_{L}>\mathrm{SSB}_{y}^{\text {obs }} \\ \alpha\left(\mathrm{SSB}_{y}^{\mathrm{obs}}-\mathrm{SSB}_{L}\right) & \text { if } \mathrm{SSB}_{y}^{\text {obs }} \geq \mathrm{SSB}_{L}\end{cases}
$$

where $\alpha$ is the pre-specified fraction of the difference between SSB in year $y$ and the relevant SSB limit reference point. Three scenarios of this strategy were evaluated in this study.

\section{Status-dependent (SD) harvest strategy}

For the status-dependent harvest strategy, we included $S S B_{T}, S S B_{L}$, target fishing mortality $\left(F_{T}\right)$ and limit fishing mortality $\left(F_{L}\right)$. If the fishing mortality was higher than $F_{\mathrm{T}}$ then the fishery was in the status of overfishing. The stock was defined as overfished if SSB was lower than $S S B_{L}$. Fishing mortality would be reduced to a lower level when SSB was below $S S B_{T}$ or fishing mortality was above $F_{L}$, and then target catch could be calculated with the lower fishing mortality in the next year and stock biomass using catch equation (Fig. 3, Zhang et al. 2011). These scenarios were derived from the MSYthreshold management strategy except for their BRP values, aiming to search for F-based and biomassbased BRP combinations in achieving pre-defined management objectives. The BRPs tested in this study are summarized in Table 2 . Some frequently used BRPs were calculated by per-recruit models in this study, including $F_{0.1}, F_{\max }, F_{35 \%}$ and $F_{20 \%}$, while the other BRPs were obtained from IOTC (2008). Because the data came from different sources in this study, there might be inconsistency among some of the reference points when we consider combinations of different reference points for different scenarios in the simulation. However, any such inconsistency would be reflected in the evaluation, and the conclusion regarding the performance of different management strategies would not be affected.

\section{Performance measures}

Choices of performance measures depend upon management objectives. Due to lack of information about specific management objectives, we set a rather general management objective to keep a stable catch while avoiding stock being overfished. Based on this objective, we identified measures that could be used to summarize simulation outcomes and compare performance of different management strategies. These measures include: 1) average annual catch over all the years considered for the projection; 2) the coefficient of variation for catch among the years; 3) average spawning biomass for all the projection years; 4) the lowest biomass during the projection years; 5) probability of the annual spawning biomass (over years and simulations) below $S S B_{m s y} ; 6$ ) probability of the annual spawning biomass below $S S B_{m s y} / 2$; and 7) average annual fishing mortality for all the projection years. These measures were calculated for each simulation run, and the averages of these measures were calculated for all the simulation runs.

These seven measures can capture the key characteristics of both resource exploitation (measures 1,2 and 7 above) and conservation (measures 3 to 6 above). Keeping spawning biomass above $S S B_{m s y}$ while achieving high and stable catch would be desirable (IOTC 2010). According to the recent IOTC resolution, the SSB should be above the level that could provide MSY for bigeye tuna (i.e. $S S B_{m s y}$ ) to ensure sustainable utilization (IOTC 2010). To prevent the fishery from collapsing, we set a limit of SSB, which is the half of $S S B_{m s y}$, and traced the lowest biomass during the time duration considered in the simulation. Clearly there are trade-offs between exploitation and conservation measures described above. According to the management objective above, we selected the best strategy amongst those considered using the following criteria: (a) the best strategy should ensure average SSB above $S S B_{m s y}$ or produce the highest SSB; and/or (b) the best strategy should achieve the highest average catch if the differences of average catch were no less than $0.05 M S Y$ (around $5600 \mathrm{t}$ in this study; MSY at 111195 tonnes, IOTC 2008). Ideally, we would like to identify a strategy that can satisfy both criteria. However, if none of the strategies can do so, we should seek those strategies that satisfy at least one of the criteria and consider other performance measures in the meantime.

\section{Sensitivity analyses}

The performance of management strategies was found to be sensitive to functional forms of the stock recruitment relationship and level of variability in future recruitment (Butterworth and Punt 1999). To evaluate impacts of assumed recruitment dynamics on management strategy evaluation, we conducted sensitivity analyses for three levels of steepness for the Beverton-Holt S-R model $(h=0.55,0.75$, and 0.95), combined with three levels of virgin recruitment $\left(R_{0}\right.$ $=23973000,47946000$ and 71919000 ) for a scenario considered the best for each management strategy. The median $h$ and $R_{0}$ were obtained from IOTC stock assessment (Shono et al. 2006, 2009, Kolody and Herrera 2010, Table 1).

\section{RESULTS}

\section{Constant fishing mortality rate strategy}

For the constant $\mathrm{F}$ strategy, constant harvest intensities were implemented at levels of $1.5 F_{m s y}, F_{m s y}$ and $0.5 F_{m s y}$ (Table 2). The second scenario of $F$ at $F_{m s y}$ $\left(0.3 \mathrm{yr}^{-1}\right)$ was designed as it was close to harvest rate in 2004 (0.297 $\mathrm{yr}^{-1}$, Table 2, Shono et al. 2006). Catch 

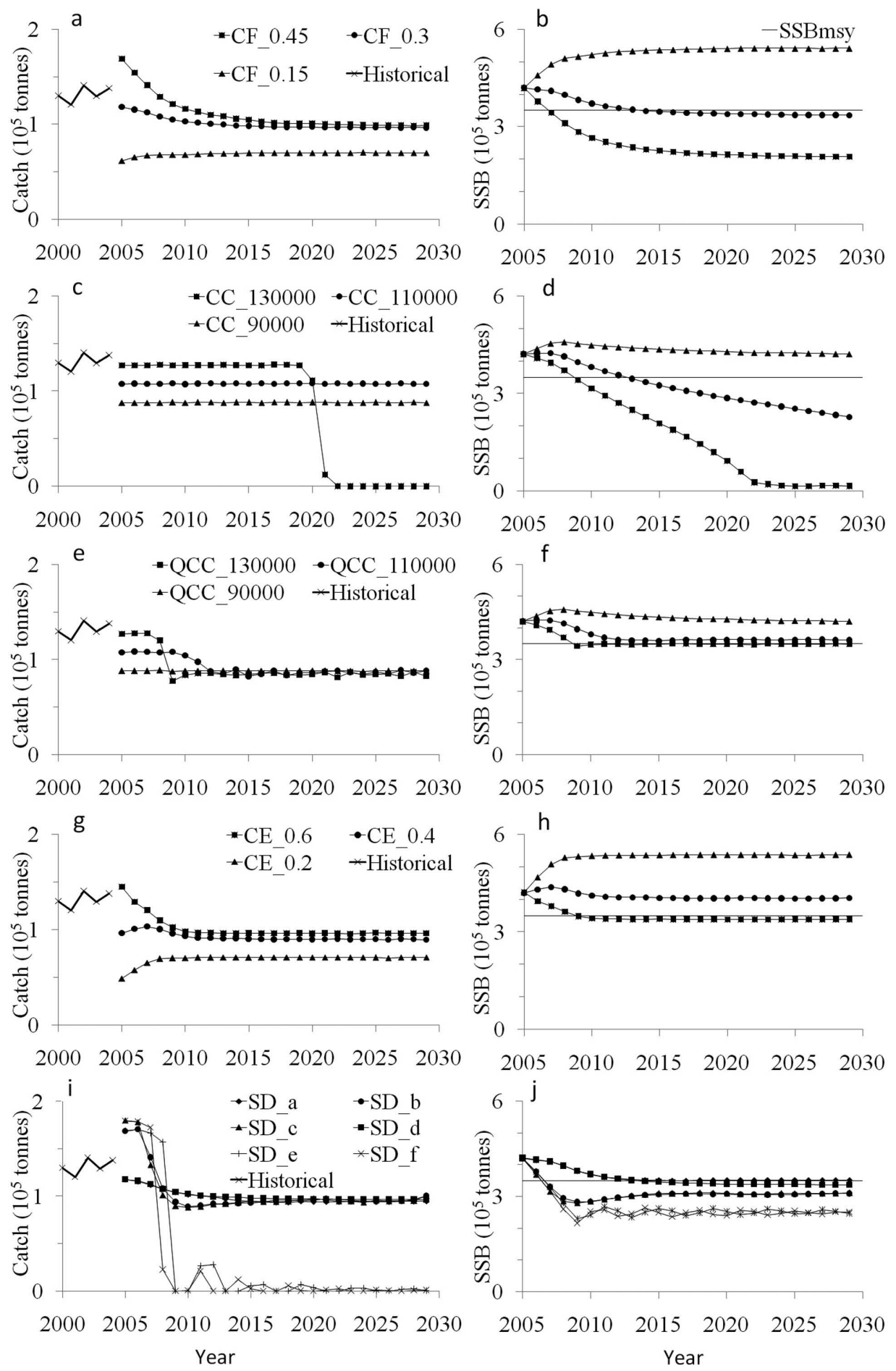

FIG. 4. - Temporal trajectories of mean catch and SSB under different management strategies (CF, constant fishing mortality; CC, constant catch; QCC, quasi-constant catch; CE, constant escapement; SD, status-dependent harvest strategy);

would gradually decrease from $118316 \mathrm{t}$ in the first year to $98564 \mathrm{t}$ in the 10 th year, and decrease slightly after the 10th year to $96403 \mathrm{t}$ at the end of the simulation (Fig. 4a). The SSB changed in similar patterns. It almost stayed constant at $336000 \mathrm{t}$ from the 10 th year, which was slightly below $S S B_{m s y}$ (Fig. 4b).
All the constant $\mathrm{F}$ scenarios in our study could eventually lead to an almost constant catch at equilibrium SSB (Fig. 4a). When a constant $F$ was applied at $0.5 F_{m s y}$ level $\left(0.15 \mathrm{yr}^{-1}\right)$, catch increased from $61736 \mathrm{t}$ in the first year to nearly $69157 \mathrm{t}$ in the 8th year, and then fluctuated around 70000 tonnes after the 8th year 
TABLE 3. - Performance measures derived from 250 simulation runs for a simulated bigeye tuna fishery managed with different management strategy scenarios for 25 years of simulation duration. The scenarios are defined in Table 2 . Means are average (over simulation) annual values for projection years. (CF, constant fishing mortality; CC, constant catch; QCC, quasi-constant catch; CE, constant escapement; SD,

\begin{tabular}{|c|c|c|c|c|c|c|c|}
\hline Scenarios & $\begin{array}{l}\text { Mean C } \\
\text { (tonnes) }\end{array}$ & $\begin{array}{c}\text { CV of } \\
\text { Mean C }\end{array}$ & $\begin{array}{c}\text { Mean SSB } \\
\text { (tonnes ) }\end{array}$ & $\begin{array}{c}\text { Lowest SSB } \\
\text { (tonnes ) }\end{array}$ & $\begin{array}{l}\text { Probability of } \\
\mathrm{SSB}_{<} \mathrm{SSB}_{\mathrm{msy}}\end{array}$ & $\begin{array}{l}\text { Probability of } \\
\mathrm{SSB}<0.5 \mathrm{SSB}_{\mathrm{msy}}\end{array}$ & $\begin{array}{c}\text { Mean F } \\
\left(\mathrm{yr}^{-1}\right)\end{array}$ \\
\hline CF_0.45 & 110889 & 0.168 & 245956 & 207408 & 0.920 & 0.000 & 0.439 \\
\hline CF_0.3 & 100610 & 0.063 & 355951 & 335362 & 0.640 & 0.000 & 0.293 \\
\hline CF_0.15 & 68925 & 0.027 & 525010 & 418767 & 0.000 & 0.000 & 0.147 \\
\hline $\mathrm{CC}_{-} 13$ & 81325 & 0.754 & 176617 & 14827 & 0.840 & 0.520 & 0.364 \\
\hline $\mathrm{CC}_{-11}^{-11}$ & 107787 & 0.0025 & 319178 & 228268 & 0.680 & 0.000 & 0.354 \\
\hline CC_9 & 88071 & 0.0021 & 433744 & 421068 & 0.000 & 0.000 & 0.219 \\
\hline QCC__13 & 90968 & 0.172 & 356802 & 343386 & 0.680 & 0.000 & 0.263 \\
\hline $\mathrm{QCC}_{-} 11$ & 91933 & 0.100 & 374305 & 359942 & 0.000 & 0.000 & 0.257 \\
\hline QCC_9 & 88147 & 0.002 & 432639 & 420551 & 0.000 & 0.000 & 0.219 \\
\hline CE_0.6 & 101218 & 0.122 & 347571 & 338399 & 0.840 & 0.000 & 0.300 \\
\hline CE_0.4 & 91938 & 0.044 & 409824 & 403434 & 0.000 & 0.000 & 0.239 \\
\hline CE_0.2 & 68932 & 0.074 & 526973 & 421893 & 0.000 & 0.000 & 0.146 \\
\hline SD_a & 98719 & 0.073 & 363553 & 350188 & 0.000 & 0.000 & 0.282 \\
\hline $\mathrm{SD}-\mathrm{b}$ & 102997 & 0.217 & 311439 & 282244 & 0.920 & 0.000 & 0.331 \\
\hline SD_c & 102823 & 0.237 & 311726 & 278973 & 0.920 & 0.000 & 0.331 \\
\hline SD_d & 100591 & 0.063 & 355968 & 336404 & 0.640 & 0.000 & 0.293 \\
\hline SD_e & 30159 & 2.019 & 266112 & 230464 & 0.920 & 0.000 & 0.098 \\
\hline SD_f & 24233 & 2.388 & 262429 & 215933 & 0.920 & 0.000 & 0.076 \\
\hline
\end{tabular}

Note: Optimal scenarios are marked in frame.

(Fig. 4a). This equilibrium catch was almost $27000 \mathrm{t}$ lower than that for scenario CF_0.3, but the equilibrium SSB of this scenario was much higher (Table 3 ).

In contrast to the conservation measures, the mean catch levels could be as high as $110889 \mathrm{t}$ if annual $F$ was kept at the $1.5 F_{m s y}$ level $\left(0.45 \mathrm{yr}^{-1}\right)$, nearly 10000 tonnes higher than that for scenario CF_0.3 (Table 3). However, the equilibrium catches for the two scenarios were close, and the equilibrium SSB for scenario CF_0.45 was lowest (Fig. 4b) and also lower than the target level $S S B_{m s y}(350000 \mathrm{t})$. The annual SSB decreased gradually all the time and stayed below $S S B_{m s y}$ from the third year (Fig. 4b). For the three constant F scenarios, keeping $\mathrm{F}$ at $0.3 \mathrm{yr}^{-1}$ (assumed to be the $F_{m s y}$ level) seemed to be best according to the criteria we defined for the performance measures, because its mean and equilibrium SSB were not less than the $S S B_{m s y}$ level and the mean and equilibrium catch level were just slightly below the 2008 level (107039 t, Herrera and Pierre 2009). Although the resulting annual SSB was slightly below the $S S B_{m s y}$ level after the 10 th year, it was still above 335000 tonnes during the 25 projection years (Fig. 4b).

\section{Constant catch strategy}

The result showed that the stock could be sustainable when annual catch was 90000 tonnes with SSB being maintained around 420000 tonnes (Fig. 4c). An annual catch of above 110000 tonnes would cause a decline of stock biomass in the long run (Fig. 4d). The fishery would have to be closed after 15 years as a result of low SSB if an annual catch of 130000 tonnes was used. Although the fishery did not need to be closed for scenario CC_11, the SSB decreased gradually, being around 230000 tonnes at the end of 25 projection years, and probably continued decreasing, leading to the eventual closure of the fishery (Fig. 4d). This sug- gests that a constant annual catch of 90000 tonnes was most rational among the three constant catch scenarios considered based on the defined performance criteria.

\section{Quasi-constant catch strategy}

Large differences were found between the constant catch strategy and the quasi-constant catch strategy. Both catch and SSB could reach equilibrium levels for the quasi-constant catch strategy (Fig. 4e, f). Annual catches were different for each scenario from the beginning to the 7 th year as different catch targets could be reached when SSB was higher than $S S B_{m s y}$ in previous years, but similar from the 8th year to the end of simulation at the level of $88000 \mathrm{t}$ (Fig. 4f). The SSB values were close for scenarios QCC_13 and QCC_11, maintaining around 350000 and $360000 \mathrm{t}$, respectively, a lower level than the $420000 \mathrm{t}$ for scenario QCC_9 (Fig. 4f). Because the mean catch and SSB were slightly higher for strategy QCC_11 than for QCC_13, the likelihood that the stock was in a desirable status (i.e. SSB higher than $S S B_{m s y}$ ) was higher for strategy QCC_11, and mean fishing mortality was lower for strategy QCC_11 (Table 3). Strategy QCC_11 tended to be the best choice of the three quasi-constant catch strategies based on the defined performance criteria.

\section{Constant escapement strategy}

Three exploitation rates considered for the constant escapement strategy were $0.6,0.4$ and 0.2 , respectively (Table 2), and threshold SSB was set at $0.5 S S B_{m s y}$. Like the constant catch scenarios, all the constant escapement strategies would result in a steady catch and equilibrium SSB after the 6th year of simulated exploitation (Fig. 4g, h). Although the total mean catch and equilibrium catch were slightly higher for scenario CE_0.6 than for scenario CE_0.4, the former's equi- 
librium SSB was $339000 \mathrm{t}$, which was below $S S B_{m s y}$. The stock always remained in a desirable status for scenarios CE_0.4 and CE_0.2 (Table 3; Fig.3h). For scenario CE_0.2, mean catch was nearly $69000 \mathrm{t}$ (Table 3), far below the catch in the actual fishery (Fig. $4 \mathrm{~g})$. Thus, scenario CE_0.4 was the most desirable of the three constant escapement strategies based on the defined criteria.

\section{Status-dependent harvest strategy}

Managing the fishery under the framework of scenario SD_a (Table 2) tended to yield a more appropriate result than managing it under other scenarios of precautionary harvest strategies. Only scenarios SD_a and SD_d could ensure a mean SSB above $S S B_{m s y}$, while the mean SSBs of scenarios SD_b and SD_c were almost 40000 t below $S S B_{m s y}$ (Table 3). Scenarios SD_e and SD_f might even cause the closure of the fishery. Meanwhile, scenario SD_b tended to have slightly higher catch for SD_d, which in turn had a slightly higher catch (by nearly 1900 t) than SD_a, but only scenario SD_a could result in SSB being always above $S S B_{m s y}$, and its lowest SSB were higher than other scenarios of the status-dependent harvest strategy (Table 3; Fig. 4i, j). Thus, SD_a might be better than the other scenarios according to the defined criteria for performance measures.

\section{Sensitivity analyses}

The projected stock dynamics tended to be sensitive to the assumed values of steepness and virgin recruitment. The changes in SSB and catch caused by different virgin recruitments seemed to be much larger than those caused by steepness for all tested scenarios, while different steepness values resulted in larger impacts on SSB than catch (Fig. 5). For example, equilibrium SSB for scenario CF_0.3 with $R_{0}$ at 47946000 was more than twice that with $R_{0}$ at 23973000 despite different steepness values, and was up to 3.5 times equilibrium $\mathrm{SSB}$ when $R_{0}$ was assumed at 71919000 . The trend of SSB for scenario CF_0.3 seemed to be similar for different levels of $R_{0}$. Differences in catch among the

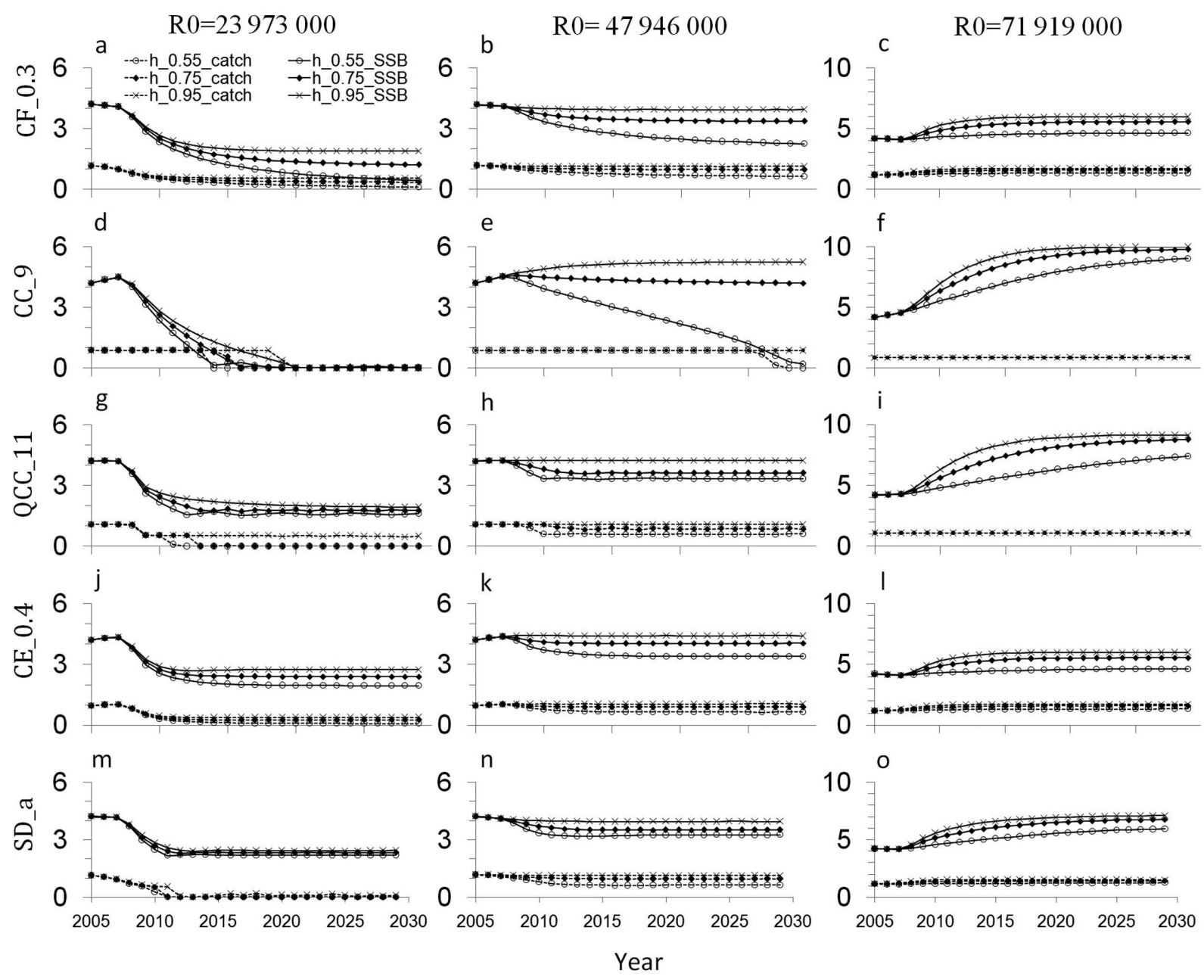

FIG. 5. - Temporal trajectories of catch (dashed lines) and SSB (solid lines) of five management strategy scenarios with different levels of virgin recruitment and steepness parameter in the Beventon-Holt stock recruitment model. 
three values of steepness were relatively small, and decreased with $R_{0}$. Catch was almost doubled when steepness increased from 0.55 to 0.95 for most projection years (Fig. 5a-c). The largest temporal variation in SSB occurred in scenario CC_9 (Fig. 5d-f).

The impacts of these uncertainties also varied with management strategies, with strategies QCC, CE and SD being more robust regarding uncertainty in recruitment dynamics (Fig. 5g-o). For the steepness of 0.75 , SSB decreased initially and would not become stable between 180000 and 270000 tonnes until the year 2014 for all the three levels of $\mathrm{R}_{0}$ (Fig. $5 \mathrm{~g}-\mathrm{o}$ ). Scenarios SD_a and CE_0.4 could ensure a higher and more stable SSB than other scenarios when the $\mathrm{R}_{0}$ was assumed to be low, but catch would decrease after year 2011 for scenarios SD_a.

\section{Comparing different strategies}

For each of the five groups of management strategies considered, the best choices for the bigeye fishery in the Indian Ocean were scenarios CF_0.3, CC_9, QCC_11, CE_0.4 and SD_a. For these management strategy scenarios, the mean SSBs were above $S S B_{m s y}$, while mean catches ranged from $88000 \mathrm{t}$ for scenario CC_9 to $100000 \mathrm{t}$ for scenario CF_0.3 (Table 3). If the probability of stock being overfished was believed to be suitably low when mean SSB was higher than $S S B_{\text {msy }}$, scenario CF_0.3 performed best according to the defined criteria. However, although the mean SSB was higher than $S S B_{m s y}$ for scenario CF_0.3, there was a $64 \%$ probability of SSB being lower than $S S B_{m s y}$ in the simulation, while there were almost no risks of SSB being below $S S B_{m s y}$ for the other four scenarios. If the objective of fishery management is to harvest in a sustainable and precautionary way, scenario CC_90 000 should be considered because it maintained SSB above $420000 \mathrm{t}$ in the simulation, although its mean catch was slightly lower than that of the other four scenarios (Table 3). In addition, there were two other advantages for scenario CC_9: a low among-year coefficient of variation $(\mathrm{CV})$ for the annual catch (Table 3 ) and easy implementation in a quota-based management system, which is implemented in the management of the Indian Ocean tuna fisheries.

One of the disadvantages for scenarios CF_0.3 and CC_9 was lack of feedback on the dynamics of fish populations. According to the constant fishing mortality rule, the harvest rate is at a fixed level irrespective of stock abundance, and annual catch is determined by $F$ and stock abundance using the catch equation. If large environmental fluctuations result in a higher natural mortality and a low recruitment, stock might be overfished if fishing mortality or annual catch was not adjusted accordingly and still kept constant. In contrast, scenarios QCC_11, CE_0.4 and SD_a were less risky for their feedback processes, with exploitation rates being reduced when SSB declined to a defined level. It seems that those strategies with built-in feed- back are desirable, adjusting catch or exploitation level based on SSB. However, they may be subject to other problems. Yearly SSB values for feedback are usually obtained from stock assessment. However, uncertainty in stock assessment for the bigeye fishery in Indian Ocean is probably large, as shown by large differences between stock assessments done by different members of Working Group for Tropical Tuna of the IOTC. Taking the estimation of MSY as an example, it is as high as $190561 \mathrm{t}$ in the updated stock assessment with the Stock Synthesis 3 model (SS3, Shono et al. 2009), $137040 \mathrm{t}$ with the SS2 model (Shono et al. 2006), and 89090 to $111195 \mathrm{t}$ with the ASPM model (Nishida et al. 2002, Ricard and Basson 2002, Shono et al. 2004). The large uncertainty in stock assessment may lead to large errors in determining the status of the stock and subsequently the development and implementation of management regulations.

Given the defined criteria, scenario SD_a was the best choice among the three scenarios with feedback because it had the highest average catch (Table 3). However, it is built with a complicated feedback process in which both stock biomass and fishing mortality are indispensable. Strategy QCC_11 could also be considered because only stock biomass is needed in feedback process, and its performance is also satisfactory. Although annual catch decreased from the 5th year, SSB and annual catch reached their equilibrium levels from the 8th year, harvesting $87000 \mathrm{t}$ while maintaining SSB around $360000 \mathrm{t}$. Another advantage for strategy QCC_11 is that there was no need to greatly reduce catch in the first six years.

\section{DISCUSSION}

The IOTC Scientific Committee recommended that catches of bigeye tuna should not exceed 110000 $\mathrm{t}$ in 2010 (IOTC 2010) and $102000 \mathrm{t}$ in 2012 (IOTC 2012). However, an annual catch of $90000 \mathrm{t}$ is recommended in this study. The difference may result from the use of different models in describing population dynamics. The SS3 model was used in the recent stock assessment, but the model used in our study is an age-structured production model, which is also used by the IOTC. MSY was estimated at 89090 t, 97400 $\mathrm{t}$ and $102928 \mathrm{t}$ with similar age-structured production model (Ricard and Basson 2002, Nishida and Shono 2006, Nishida and Rademeyer 2011). Uncertainties associated with parameters may be another reason for the difference in the recommended annual catch level. We used the Monte Carlo simulation method, assuming lognormal distribution for uncertainties and then used statistics derived from the outputs of 250 simulation runs, instead of weighting the outputs of submodels in Kolody and Herrera (2010).

The IOTC Scientific Committee also stated that immediate management measures are not required if the recent declines in effort continue, which might result from the expansion of the areas affected by Somalia 
piracy in the core fishing area in the northwest Indian Ocean in recent years (IOTC 2012). This led to a marked drop in catches in 2009 and 2010. At the mean time the catch per unit effort increased, which might indicate that stock abundance might be higher. This shows that restricting fishing effort may be more efficient to limit the annual catch when stock abundance is not much more than the biomass capable of producing MSY, which is consistent with the results of our study. It is interesting that piracy could greatly reduce fishing in certain areas, effectively creating closed areas, which might protect components of fish stock. This example shows that setting a closed area to restrict fishing may be helpful to reduce overall fishing efforts and subsequently the likelihood of stock being overfished, especially for new fisheries or fisheries with poor data availability. For tuna fisheries, in fact, a closed area has been established in the western and central Pacific Ocean, which was believed to make a contribution to controlling the annual catch (Anonymous 2008, Davies et al. 2011).

In other oceans, bigeye tuna fisheries are managed based on stock assessment results, including catch reduction for longline fishery and temporal/spatial closure and fishing mortality reduction for purse seine fishery. At the annual meeting of the Inter-American Tropical Tuna Commission in 2009, the resolution agreed to stop the purse seine fishery in the eastern Pacific Ocean for a period of 59 days in 2009, 62 days in 2010, and 73 days in 2011, and to impose limits on longline catches for three Asian countries from 2009 to 2011, because the stock assessment showed that the stock was below $B_{M S Y}$ (IATTC 2009). In the Atlantic Ocean, the International Commission for the Conservation of Atlantic Tuna (ICCAT) recommended limiting fishing vessel sizes and Chinese Taipei catches because the stock was believed to be overfished, though overfishing occurred from 1998 to 2004. From 2004, a total allowable catch of $90000 \mathrm{t}$ was adopted (Allen 2010). Limiting catch and fishing mortality are major management measures in the Western and Central Pacific Fisheries Commission (WCPFC). The most recent conservation and management measures in the WCPFC aim to limit annual catch, especially for countries that harvested more than $2000 \mathrm{t}$ on average from 2001 to 2004 , and to reduce fishing mortality by at least 30\% (WCPFC 2008). However the effectiveness of these management strategies needs to be evaluated using an approach similar to the one we developed in this study. Without such an evaluation, we only have limited understanding of possible consequence of proposed management strategies, and also may miss the opportunity to identify suitable management strategy.

As different management strategies may respond differently to uncertainty in recruitment dynamics, it is essential to choose a strategy that is robust to the uncertainty to reduce the likelihood of overfished stock and overfishing. In this study, it is clear that strategies such as strategies QCC, CE and SD (Fig. 5g-o) with feedback to respond to the stock status are more robust, because they reduce catch quota when stock is believed to be at a low level. In our study, stock is assumed overfished when SSB is lower than $S S B_{m s y} / 2$ for the five "optimal" scenarios. If the stock is defined as overfished, management measure is taken immediately. When this happened at a low $R_{0}$ in this study, scenarios QCC_11, CE_0.4 and SD_a yielded similar results with respect to temporal changes in SSB and catch. It is difficult for a strategy without a feedback control (such as strategies CF and CC) to prevent stock from being overfished, especially for the constant catch strategy. Even with a constant catch of $90000 \mathrm{t}$, which was much lower than the current annual catch, the stock might still be overfished under a low productivity. Given the uncertainty in recruitment dynamics, it is important to adopt a management strategy that can respond to the change in stock status in a timely manner.

Although we considered uncertainty for various life history and fishery processes, this study is not a full management strategy evaluation because no updated stock assessment was done during the 25 time periods when the assumed management strategies are evaluated. We did add random errors to population parameters used in the projection of population dynamics. However, these errors may differ in nature from those inherent in a stock assessment. For example, we added random errors to SSB values without considering temporal auto-correlations. These simulated SSB may differ in nature from the SSB values estimated in a stock assessment, which tend to be subject to temporally auto-correlated errors. Given the uncertainty and limitation, the management implication of this study should be interpreted with caution.

\section{ACKNOWLEDGEMENTS}

This study was funded by the Shanghai Ocean University Graduate School (PhD dissertation grant), National High-tech R\&D Programme of China (863 Programme; 2012AA092301; 2012AA092303), Project of Shanghai Science and Technology Innovation (12231203900), Industrialization Programme of the National Development and Reform Commission (2159999), and the Shanghai Leading Academic Discipline Project. This study was also supported by the National Distant-Water Fisheries Engineering Research Centre and the Scientific Observing and Experimental Station of Oceanic Fishery Resources, Ministry of Agriculture, P.R. China. Y. Chen's involvement in the project was supported by the SHOU International Centre for Marine Studies.

\section{REFERENCES}

Allen R.L. 2010. International management of tuna fisheries: arrangements, challenges and a way forward. FAO Fisheries and Aquaculture Technical Paper. No. 536. Rome, FAO, 45 pp.

Anonymous, 2008. Review of CCMs' Implementation of, and Compliance with, Conservation and Management Measures. 
WCPFC-TCC4-2008/31 (Rev.1), 22 pp

Bentley N., Langley A. D. 2012. Feasible stock trajectories: a flexible and efficient sequential estimator for use in fisheries management procedures. Can. J. Fish. Aquat. Sci. 69(1): 161-177.

Bentley N., Breen P.A., Kim S.W., Starr P.J. 2005. Can additional abundance indices improve harvest control rules for New Zealand rock lobster (Jasus edwardsii) fisheries? N. Z. J. Mar. Freshw. Res. 39(3): 629-644.

Breen P.A. 2009. A voluntary harvest control rule for a New Zealand rock lobster (Jasus edwardsii) stock. N. Z. J. Mar. Freshw. Res. 43(4): 941-951.

Butterworth D.S., Punt A.E. 1999. Experiences in the evaluation and implementation of management procedures. ICES J. Mar. Sci. 56: 985-998.

Butterworth D.S. 2007. Why a management procedure approach? Some positives and negatives. ICES J. Mar. Sci. 64: 613-617.

Chen Y., Paloheimo J.E. 1995. A robust regression analysis of recruitment in fisheries Can. J. Fish. Aquat. Sci. 52: 993-1006.

Davies N., Hoyle S.D., Harley S.J., Langley A.D., Hampton J. 2011. Stock Assessment of Bigeye Tuna in the Western and Central Pacific Ocean. WCPFC-SC7-2011/SA-WP-02, 133 pp.

Deroba J.J., Bence J.R. 2008. A review of harvest policies: Understanding relative performance of control rules. Fish. Res. 94: 210-223.

Herrera M., Pierre L. 2009. Estimation of catch-at-size and total catch per area for tropical tuna species. IOTC-2009-WPTT-12, 32p.

Hjerne O., Hansson S. 2001. Constant catch or constant harvest rate? - The Baltic Sea cod (Gadus morhua L.) fishery as a modelling example. Fish. Res. 53: 57-70.

IATTC, 2009. Resolution on a Multiannual Program for the Conservation of Tuna in the Eastern Pacific Ocean in 2009-2011 (Resolution C-09-01). Inter-American Tropical Tuna Commission, 80th meeting, California, USA, 4 pp. http://www. iattc.org/PDFFiles2/Resolutions/C-09-01-Tuna-conservation-2009-2011.pdf

IOTC, 2008. Executive summaries of the status of the major ocean tunas. IOTC-2008-SC-03[E+F] -rev1, $44 \mathrm{pp}$.

IOTC, 2010. For the conservation and management of tropical tunas stocks in the IOTC area of competence (Resolution 10/01). In: Collection of Resolution and Recommendations by the Indian Ocean Tuna Commission. Resolution 10/01, pp. 164-168. http://www.iotc.org/files/proceedings/misc/ComReportsTexts/ resolutions_E.pdf

IOTC, 2012. Report of the Fifteenth Session of the IOTC Scientific Committee. IOTC-2012-SC15-R[E], 288 pp.

Ishimura G., Punt A.E., Huppert D.D. 2005. Management of fluctuating fish stocks: the case of Pacific whiting. Fish. Res. 73: 201-216.

Kell L.T., O’Brien C.M., Smith M.T., Stokes T.K., Rackham B.D. 1999. An evaluation of management procedures for implementing a precautionary approach in the ICES context of North Sea plaice (Pleuronectes platessa L.). ICES J. Mar. Sci. 56: 834-845.

Kolody D., Herrera M. 2010. Exploration of Indian Ocean Bigeye Tuna Stock Assessment Sensitivities 1952-2008 using Stock Synthesis. IOTC-2010-WPTT-04, 75 pp.

Nakamura E.L., Uchiyama J.H. 1966. Length-weight relations of Pacific tunas. In: Manar T.A. (ed.) Proceeding of the Governor's conference on central Pacific Fisheries Resources. Honolulu, State of Hawaii, pp. 197-201.

Needle C.L. 2008. Management strategy evaluation for North Sea haddock. Fish. Res. 94: 141-150.

Nishida T., Rademeyer R. 2011. Stock and risk assessments on bigeye tuna (Thunnus obesus) in the Indian Ocean based on AD Model Builder implemented Age-Structured Production Model (ASPM). IOTC-WPTT13-2010-42, 23 pp.

Nishida T., Shono H., Okamoto H., Suzuki Z. 2002. Updated bigeye tuna (Thunnus obesus) resource analyses in the Indian Ocean -
CPUE, ASPM (MSY) and projections. IOTC Proc. 5: 475-481.

Nishida T., Shono H. 2006. Updated stock assessment of bigeye tuna (Thunnus obesus) resource in the Indian Ocean by the agestructured production model (ASPM) analyses (1960-2004). IOTC-WPTT-2006-22, 19 pp.

Polacheck T., Klaer N.L., Millar C., Preece A.L. 1999. An initial evaluation of management strategies for the southern bluefin tuna fishery. ICES J. Mar. Sci. 56: 811-826.

Poreeyanond D. 1994. Catch and size groups distribution of tunas caught by purse seining survey in the Arabian Sea, Western Indian Ocean, 1993. In: Ardill J.D. (ed.) Proceedings of the Expert Consultation on Indian Ocean Tunas, 5th Session, Mahé, Seychelles, pp. 53-54.

Punt A.E., Hobday D. 2009. Management strategy evaluation for rock lobster, Jasus edwardsii, off Victoria, Australia: accounting for uncertainty in stock structure. N. Z. J. Mar. Freshw. Res. 43: 485-509.

Restrepo V.R., Powers J.E. 1999, Precautionary control rules in US fisheries management: specification and performance. ICES J. Mar. Sci. 56, 846-852.

Ricard D., Basson M. 2002. Application of an age-structured production model (ASPM) to the Indian Ocean bigeye tuna (Thunnus obesus) resource. IOTC-WPTT-02-07, $14 \mathrm{pp}$.

Shono H., Nishida T., Okamoto H. 2004. Future projections for bigeye tuna in the Indian Ocean. IOTC-WPTT-04-19, 14 pp.

Shono H., Okamoto H., Senba K. 2006. Preliminary Stock Assessment for Bigeye Tuna in the Indian Ocean using Stock Synthesis II (SS2). IOTC-2006-WPTT-18, 12 pp.

Shono H., Satoh K., Okamoto H., Nishida T. 2009. Updated stock assessment for bigeye tuna in the Indian Ocean up to 2008 using Stock Synthesis III (SS3). IOTC-2009-WPTT-20, 9 pp.

Smith A.D.M. 1994. Management strategy evaluation: the light on the hill. In: Hancock D.A. (ed.), Population Dynamics for Fisheries Management. Australian Society for Fish Biology, Perth, Western Australia, pp. 249-253.

Stequert R., Conand F. 2003. Age and growth of bigeye tuna in the western Indian Ocean. IOTC-WPTT-03-Info2, 10 pp.

Thompson G. 1999. Optimizing harvest control rules in the presence of natural variability and parameter uncertainty. Proceedings, 5th NMFS NSAW. NOAA Tech. Memo. NMFSF/SPO-40, 45 pp.

U.S. Sustainable Fisheries Act, 1996. Magnuson-Stevens Fishery Conservation and Management Act. Section 301.

Walters C. 1998. Evaluation of quota management policies for developing fisheries. Can. J. Fish. Aquat. Sci. 55: 2691-2705.

Walters C., Parma A.M. 1996. Fixed exploitation rate strategies for coping with effects of climate change. Can. J. Fish. Aquat. Sci. 53: $148-158$.

WCPFC, 2008. Conservation and Management Measures for Bigeye and Yellowfin Tuna in the Western and Central Pacific Ocean (CMM 08-01). Western and Central Pacific Fisheries Commission fifth regular session. 42 pp. http://www.wcpfc. $\mathrm{int} /$ system/files/documents/conservation-and-managementmeasures-and-resolutions/conservation-and-managementmeasures/CMM\%202008-01\%20\%5BBigeye $\% 20$ and $\% 20$ yellowfin\%5D.pdf

Zhang Y.Y., Chen Y., Wilson C. 2011. Developing and evaluating harvest control rules with different biological reference points for the American lobster fishery in the Gulf of Maine. ICES $J$. Mar. Sci. 68: 1511-1524.

Zhang Y.Y., Chen Y., Zhu J.F., Tian S.Q., Chen X.J. 2013. Evaluating harvest control rules for bigeye tuna (Thunnus obesus) and yellowfin tuna (Thunnus albacares) fisheries in the Indian Ocean. Fish. Res. 137: 1-8.

Scient. ed.: V. Stelzenmüller.

Received January 28, 2013. Accepted May 2, 2013.

Published online July 11, 2013 